\title{
Protective and risk factors for women's mental health after a spontaneous abortion*
}

\author{
Francine deMontigny ${ }^{1,2}$ \\ (D) https://orcid.org/0000-0003-1676-0189 \\ Chantal Verdon ${ }^{1}$ \\ (D) https://orcid.org/0000-0001-8019-9133 \\ Sophie Meunier ${ }^{3}$ \\ (1D) https://orcid.org/0000-0001-8877-2432 \\ Christine Gervais ${ }^{1,4}$ \\ (D) https://orcid.org/0000-0001-5695-9358 \\ Isabel Coté ${ }^{1}$ \\ (1) https://orcid.org/0000-0002-3529-7225
}

\footnotetext{
* Supported by Fonds Québécois de Recherche en Santé, 26811, Canada.

1 Université du Québec en Outaouais, Gatineau, Qc, Canada.

2 Scholarship holder at the Canadian Research Chair in Psychosocial Family Health, Canada.

3 Université du Québec à Montréal, Montreal, Qc, Canada.

${ }^{4}$ Scholarship holder at the Fonds Québécois de Recherche en Santé, Canada.
}

Objective: to examine personal and contextual protective and risk factors associated with women's mental health after a spontaneous abortion. Method: a cross-sectional study was carried out where 231 women who had experienced spontaneous abortions in the past 4 years answered a selfreporting online questionnaire to assess their mental health (symptoms of depression, anxiety, perinatal grief) and to collect personal as well as contextual characteristics. Results: women who had experienced spontaneous abortions within the past 6 months had higher scores for depressive symptoms than those who had experienced spontaneous abortions between 7 and 12 months ago, while anxiety level and perinatal grief did not vary according to the time since the loss. Moreover, low socioeconomic status, immigrant status, and childlessness were associated with worse mental health after a spontaneous abortion. In contrast, the quality of the conjugal relationship and the level of satisfaction with health care were positively associated with women's mental health. Conclusion: women in vulnerable situations, such as immigrants, women with a low socioeconomic status, or childless women are particularly vulnerable to mental health problems after a spontaneous abortion. However, beyond those personal and contextual factors, the quality of the conjugal relationship and the level of satisfaction with health care could be important protective factors.

Descriptors: Abortion, Spontaneous; Nursing; Women; Mental Health; Emigrants and Immigrants; Protective Factors.

\section{How to cite this article}

deMontigny F, Verdon C, Meunier S, Gervais C, Coté I. Protective and risk factors for women's mental health after a spontaneous abortion. Rev. Latino-Am. Enfermagem. 2020;28:e3350. [Access Available in: DOI: http://dx.doi.org/10.1590/1518-8345.3382.3350. 


\section{Introduction}

In Western societies, it has been estimated that approximately $20 \%$ of the pregnancies end in spontaneous abortions (also known as miscarriages) within the first 22 weeks ${ }^{(1-2)}$. The exact numbers are not known, as most countries only collect statistics for later perinatal deaths, that is, after the $24^{\text {th }}$ gestational week or when the foetus weighs more than one pound ${ }^{(3)}$. Despite this high prevalence, bereavement associated with spontaneous abortions has received much less attention from the scientific and professional communities than that associated with any other type of death ${ }^{(4-5)}$. The repercussions of bereavement related to early perinatal loss are nevertheless a significant issue for society, particularly in terms of public health, since a number of studies have indicated its important deleterious effects on women's mental health ${ }^{(6-8)}$. Those findings raise an important question about protective and risk factors that may exacerbate or diminish the negative effects of spontaneous abortions on women's mental health ${ }^{(9)}$. Answers to this question are crucial in order to better target women who are more at risk of developing mental health problems after a spontaneous abortion and to offer appropriate support.

There are personal and contextual variables influencing women's mental health after a miscarriage. A few authors have examined different personal and contextual variables that may influence women's mental health after a spontaneous abortion and which act as protective or risk factors. Regarding the personal variables, some findings indicated that sociodemographic factors (e.g., age, socioeconomic status) were not associated with women's mental health after a spontaneous abortion ${ }^{(3,6)}$. However, the majority of the studies on the experience of spontaneous abortion were conducted among white middle-class women living in a marital relationship ${ }^{(3)}$. Women living in conditions of vulnerability (low income, less schooling, or immigrant status) ${ }^{(3)}$ have received less research attention; as such, there is a need to assess the influence of these variables among more heterogeneous samples. In this vein, a study carried out with a large sample of Australian women found that the schooling level was positively associated with mental health after a spontaneous abortion $^{(10)}$. The contextual variables of childlessness, advanced gestational age, and spontaneous abortion history were identified as factors that intensify perinatal bereavement ${ }^{(6,11)}$. However, except for childlessness, the results concerning these variables are inconsistent. Indeed, some researchers found that advanced gestational age and prior loss were associated with worse mental health ${ }^{(11-13)}$, while others found no significant association $^{(11)}$

The support offered to the parents by family members and friends or by health care professionals is another variable of interest. The result of an earlier study indicates that support from their spouse was especially important in helping women cope with spontaneous abortions ${ }^{(14)}$. Thus, it may be that the quality of the conjugal relationship has more influence on women's mental health after a spontaneous abortion than the simple fact of being in a couple. The level of satisfaction with health care may also be important to mitigate the deleterious effects of spontaneous abortions on women's mental health. Indeed, health care professionals are key actors in the health pathway of couples living through the experience of a spontaneous abortion(4,15). However, even though the experience and repercussions of bereavement have been studied, women's experiences of professional interventions-or the absence thereofhave received minimal research attention.

Findings from the few qualitative studies on the women's experience of spontaneous abortions have indicated that they most often report being dissatisfied with the health care received before, during, and after their spontaneous abortions ${ }^{(4-5)}$. Women lament the lack of compassion(14), of social and emotional support(16-17), and of information provided by the health care professionals ${ }^{(4-5,14,16)}$. From a quantitative perspective, the level of satisfaction with the primary care physician ${ }^{(10)}$ has been associated with better mental health, highlighting the important role of these health professionals in the recovery from a spontaneous abortion. However, other health care professionals (e.g., nurse, social worker) who might be involved in the care of women who had experienced a spontaneous abortion were not considered in this study(10). In summary, the complex psychological phenomenon of a spontaneous abortion remains poorly studied, except with regard to grief reactions. Moreover, few researchers have examined women's mental health after a spontaneous abortion in relation to their personal and contextual characteristics and the results have been inconsistent.

The objective of this study was to examine personal and contextual protective and risk factors associated with women's mental health after a spontaneous abortion. The authors aimed to investigate whether the mental health of women who experienced spontaneous abortions varied in relation to various personal risk factors related to their age, socioeconomic status (income and schooling), and immigrant status. The authors also examined the effect of contextual risk factors, such as childlessness, number of gestational weeks, number of spontaneous abortions, and time 
elapsed since the spontaneous abortion, on these women's mental health. Finally, the authors examined the association between two potential protective factors, the quality of the conjugal relationship and the level of satisfaction with health care, and the mental health of women who have experienced a spontaneous abortion.

\section{Method}

This cross-sectional study was conducted in the province of Québec, Canada, where an estimated 20,000 miscarriages occur for 86,000 live births ${ }^{(18)}$. It was approved by the research ethics board of the Université du Québec en Outaouais \#1799. Ads were posted in medical clinics, on social media and on various websites, inviting women who had experienced a spontaneous abortion within the past four years to participate in the study. To be eligible to participate, women had to: 1 ) be aged 18 years or older; 2 ) have experienced at least one spontaneous abortion in the past four years; and 3 ) be able to read French. There were no exclusion criteria. The eligible participants were invited to read and sign a consent form and to answer an online questionnaire on a secure web platform. A total of 231 women completed the self-reporting questionnaire, which consisted of a set of six measures assessing mental health, personal and contextual variables, the quality of the conjugal relationship, and the level of satisfaction with health care.

Mental health: Depressive symptoms were assessed using the French version of the Edinburgh Postnatal Depression Scale(19-20). On a 4-point Likert scale, the participants indicated how they felt in the past 7 days (e.g., I have felt sad or miserable). The 10 items were summed up to form a global depression score $(a=.88)$. A score of 10 or higher was used as a cut-off point for possible depression ${ }^{(19)}$. Anxiety was assessed using the 20 items of the state subscale of the French version of the State-Trait Anxiety Inventory (STAI-S) ${ }^{(21-22)}$. On a 4-point Likert scale, the participants indicated how they felt right now, at this moment (e.g., I feel upset). The reversed scores were recoded and the items were summed up to produce a global anxiety score $(a=.94)$. Perinatal grief was measured using the French version of the Perinatal Grief Scale ${ }^{(23-24)}$. On a 5-point Likert scale, the participants indicated their agreement with 33 statements related to the loss of their baby (e.g., I get upset when I think about the baby). The reversed scores were recoded and the items were summed up to produce a global perinatal grief score $(a=.94)$.

Personal and contextual variables: The participants indicated their highest level of schooling, their family income, and their immigrant status. The answers related to schooling were grouped into three categories based on the diplomas or degrees obtained: high school, college (technical/vocational or pre-university), and university. Family income was categorized as $\leq 49,999$ Canadian dollar (CAD), 50,000-99,999 CAD, or $\geq 100,000$ CAD. The immigrant status was categorized into two groups: Non-immigrant (born in Canada) and Immigrant (other country of origin). The participants also indicated the date of their last spontaneous abortion, the number of previous spontaneous abortions, their age at the time of the last spontaneous abortion, and the gestational age of that foetus. The two latter variables were used as continuous variables. The time since the spontaneous abortion was classified as within the past 6 months, between 7 and 12 months, between 1 and 2 years, and between 2 and 4 years, while the number of spontaneous abortions was classified as 1, 2, or 3 or more. Finally, the participants indicated whether they had any living children of whom they were biological parents (yes/no).

Quality of the conjugal relationship: The quality of the conjugal relationship was measured using 4 items of

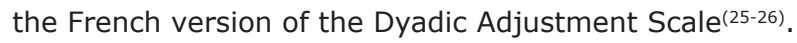
On a 6-point Likert scale, the participants indicated their overall degree of happiness in their relationship and how often specific situations relating to their relationship usually happened (e.g., In general, how often do you think that things between you and your partner are going well?). Internal consistency was satisfactory $(a=.81)$.

Satisfaction with health care: The level of satisfaction with health care was assessed using the Institutional Support Evaluation Scale(27). On a 4-point Likert scale, the participants indicated how helpful they perceived a list of 19 different health services received during the course of their spontaneous abortion (nurse, physician, gynecologist) or afterwards (support groups). The participants could also indicate "not applicable" if they had not received the service. The scores for each service received were averaged to obtain a global satisfaction score $(a=.95)$.

The analyses were performed using SPSS v.22 (IBM). There were no missing variables for the measures of mental health and quality of conjugal relationship. For the level of satisfaction with health care, personal and contextual variables, there were few missing data per variable (from 1 to 7 per variable - less than 4\%). Since these data were also randomly distributed, they were not imputed, and listwise deletion was used for main analysis ${ }^{(28)}$. Descriptive statistics (mean, standard deviation, proportion) was conducted to characterize the sample. One-way analyses of variance (ANOVAs) for the categorical variables, and correlations for the continuous variables, were then performed to examine associations between personal and contextual factors 
and women's mental health. Tukey post hoc tests were performed when the ANOVAs indicated a significant difference and the independent variable comprised more than two groups (e.g., income, schooling). Hierarchical regression analyses were performed to examine the association between the quality of the conjugal relationship and the level of satisfaction with health care and mental health, while controlling for personal and contextual factors. In the first step, the contextual and personal variables that were significantly associated with mental health in the ANOVAs and the correlations were entered into the analysis. The quality of the conjugal relationship was entered in a second step, followed by the level of satisfaction with health care services in a third step. The statistical power analysis performed with $\mathrm{G}^{*}$ power $^{(29)}$ indicate that, to achieve a statistical power of $95 \%$, with an average effect size, and 8 independent variables (quality of the conjugal relationship, level of satisfaction with health care, and up to six control variables), a sample of 160 participants is needed. Thus, the sample of the current study ( $\mathrm{n}=231$ ) provides a satisfactory statistical power. Figure 1 illustrates the study variables included in the analysis.

Personal Characteristics

Age, socioeconomic status (schooling, income), immigrant status

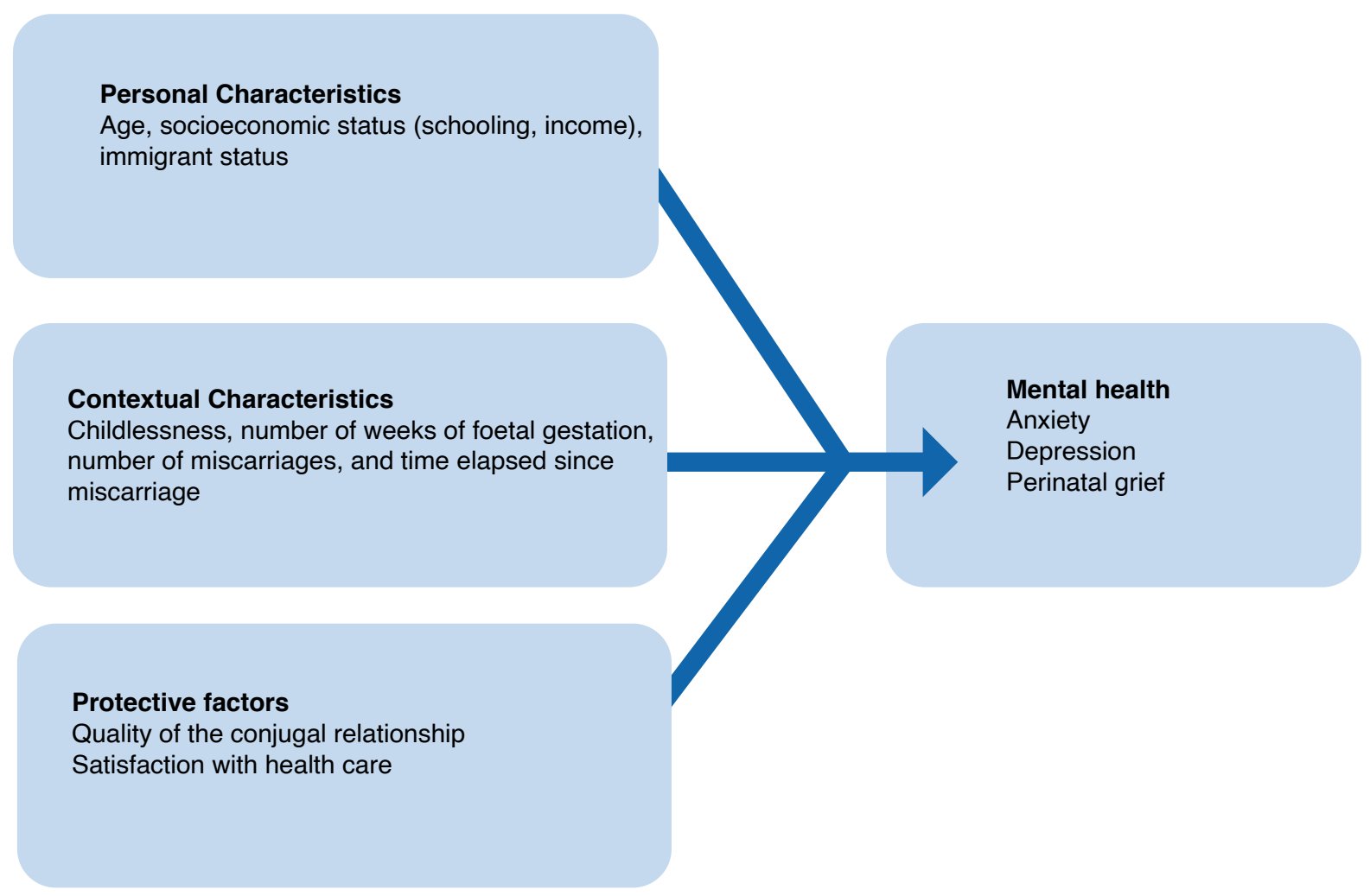

Figure 1 - Variables related to the women's mental health after a spontaneous abortion

\section{Results}

Table 1 presents descriptive statistics for the study variables. The women's ages at the time of their last spontaneous abortion ranged from 19 to 43 years old, with a majority between 25 and 35 years old $(n=170,74 \%)$. A minority of the participants were immigrants or had a low socioeconomic status. For half of the women, the spontaneous abortion had happened less than 1 year ago, with the time since the spontaneous abortion ranging from 1 month to 4 years. Foetal gestational age at the time of the spontaneous abortion ranged from 3 to 20 weeks. The number of spontaneous abortions ranged from 1 to 11 , with a majority of women having experienced 1 or 2 miscarriages. Nearly $40 \%$ of the participants were childless at the time of the study. The women were not asked if they were pregnant at the time of data collection, which could be a limitation of this study. Regarding age, income and schooling, the sample is representative of the women in the region(18).

Regarding the mental health variables, 125 (55\%) women had a depression score greater than or equal to 10 , indicating possible depression ${ }^{(19)}$, and $62(27.1 \%)$ reported high scores of perinatal grief $(>91)^{(30)}$. The anxiety mean score was moderate, and $42(18.3 \%)$ participants reported low-quality conjugal 
relationship (score $<14)^{(25)}$. Finally, on average, the participants felt relatively satisfied with the health care services (mean score of 3.11/4.00).

Table 2 presents the results of the one-way ANOVA testing differences in the mental health scores according to personal and contextual characteristics. The results first indicated that women's mental health varied in line with their income and their schooling level. In fact, post hoc tests revealed that women with a family income $\leq 49,999$ CAD had higher scores for depression, anxiety, and perinatal grief than those with a family income $\geq 50,000$ CAD, while women with a high school diploma had higher scores for perinatal grief than those with a college or university degree. Immigrant women also had higher scores for depression and perinatal grief than non-immigrant women, while childless women reported significantly more depression, anxiety, and perinatal grief symptoms. The women's depression levels differed according to the time since the spontaneous abortion. Indeed, the post hoc tests indicated that women who had miscarried within the past 6 months had higher scores for depression than those who had miscarried between 7 and 12 months ago. There were no significant differences in the mental health scores according to the number of spontaneous abortions.

Table 1 - Descriptive statistics for the study variables. Québec, Canada, 2018

\begin{tabular}{|c|c|}
\hline Variables & $\mathbf{N}(\%)$ \\
\hline \multicolumn{2}{|l|}{ Family income (CAD) } \\
\hline $0-49,999$ & $53(23.14 \%)$ \\
\hline $50,000-99,999$ & $100(43.67 \%)$ \\
\hline$\geq 100,000$ & $76(33.19 \%)$ \\
\hline \multicolumn{2}{|l|}{ Schooling level } \\
\hline High school & $34(14.85 \%)$ \\
\hline College & $67(29.26 \%)$ \\
\hline University & $125(54.59 \%)$ \\
\hline \multicolumn{2}{|l|}{ Immigrant status } \\
\hline Immigrant & $17(7.42 \%)$ \\
\hline Non-immigrant & $212(92.58 \%)$ \\
\hline \multicolumn{2}{|l|}{ Time since spontaneous abortion } \\
\hline 0-6 months & $64(27.95 \%)$ \\
\hline $7-12$ months & $58(25.33 \%)$ \\
\hline $1-2$ years & $64(27.95 \%)$ \\
\hline $2-4$ years & $43(18.78 \%)$ \\
\hline \multicolumn{2}{|l|}{ Number of spontaneous abortions } \\
\hline 1 & $150(65.50 \%)$ \\
\hline 2 & $34(14.85 \%)$ \\
\hline 3 or more & $45(19.65 \%)$ \\
\hline \multicolumn{2}{|l|}{ Childlessness } \\
\hline Yes & 87 (37.99\%) \\
\hline \multirow[t]{2}{*}{ No } & $142(62.01 \%)$ \\
\hline & Mean (SD) \\
\hline Age & $30.74(4.60)$ \\
\hline Gestational age of the foetus & $9.35(3.35)$ \\
\hline Depression (/30) & $10.85(6.40)$ \\
\hline Anxiety (/80) & $37.66(11.89)$ \\
\hline Perinatal grief (/165) & $72.02(29.02)$ \\
\hline Quality of the conjugal relationship (/20) & $15.81(3.28)$ \\
\hline Satisfaction with health care & $3.11(0.63)$ \\
\hline
\end{tabular}


The correlations analysis (Table 3 ) indicated that neither the age at the time of the spontaneous abortion nor the gestational age of the foetus were significantly associated with depression, anxiety, or perinatal grief. However, the quality of the conjugal relationship and the level of satisfaction with health care were significantly positively correlated with those three mental health variables. Depression, anxiety, and perinatal grief were also strongly positively correlated.

Table 2 - Women's mental health according to personal and contextual variables. Québec, Canada, 2018

\begin{tabular}{|c|c|c|c|c|c|c|c|c|c|c|}
\hline \multirow[b]{2}{*}{ Variables } & \multicolumn{3}{|c|}{ Depression } & \multirow[b]{2}{*}{$p$} & \multirow[b]{2}{*}{$\begin{array}{c}\text { Anxiety } \\
\text { Mean (SD) }\end{array}$} & \multicolumn{5}{|c|}{ Perinatal grief } \\
\hline & $\mathbf{N}$ & $\begin{array}{l}\text { Mean } \\
\text { (SD) }\end{array}$ & $\mathbf{F}$ & & & $\mathbf{F}$ & $p$ & $\begin{array}{l}\text { Mean } \\
\text { (SD) }\end{array}$ & $\mathbf{F}$ & $p$ \\
\hline \multicolumn{11}{|l|}{ Income (CAD) } \\
\hline $0-49,999$ & 53 & $\begin{array}{l}14.02 \\
(5.74)\end{array}$ & 9.14 & 0.000 & $\begin{array}{c}42.02 \\
(11.92)\end{array}$ & 4.83 & 0.010 & $\begin{array}{c}90.32 \\
(29.85)\end{array}$ & 15.58 & 0.000 \\
\hline $\begin{array}{l}50,000 \\
-99,999\end{array}$ & 100 & $\begin{array}{l}10.07 \\
(6.84)\end{array}$ & & & $\begin{array}{c}36.60 \\
(13.26)\end{array}$ & & & $\begin{array}{l}67.34 \\
(28.27)\end{array}$ & & \\
\hline$\geq 100,000$ & 76 & $\begin{array}{c}9.67 \\
(5.53)\end{array}$ & & & $\begin{array}{l}36.03 \\
(9.03)\end{array}$ & & & $\begin{array}{c}65.41 \\
(24.01)\end{array}$ & & \\
\hline \multicolumn{11}{|l|}{ Schooling } \\
\hline High school & 34 & $\begin{array}{l}12.59 \\
(6.19)\end{array}$ & 1.70 & 0.128 & $\begin{array}{c}40.15 \\
(12.90)\end{array}$ & 1.22 & 0.239 & $\begin{array}{c}88.82 \\
(29.24)\end{array}$ & 10.02 & 0.000 \\
\hline College & 67 & $\begin{array}{l}10.39 \\
(6.82)\end{array}$ & & & $\begin{array}{c}37.72 \\
(12.23)\end{array}$ & & & $\begin{array}{c}73.99 \\
(31.82)\end{array}$ & & \\
\hline University & 125 & $\begin{array}{l}10.44 \\
(6.08)\end{array}$ & & & $\begin{array}{c}36.62 \\
(11.17)\end{array}$ & & & $\begin{array}{c}65.40 \\
(24.57)\end{array}$ & & \\
\hline \multicolumn{11}{|l|}{ Immigration status } \\
\hline $\mathrm{No}^{*}$ & 212 & $\begin{array}{l}10.55 \\
(6.32)\end{array}$ & 6.41 & 0.013 & $\begin{array}{c}37.27 \\
(11.71)\end{array}$ & 3.18 & 0.080 & $\begin{array}{c}70.26 \\
(28.11)\end{array}$ & 10.88 & 0.001 \\
\hline Yes $^{\dagger}$ & 17 & $\begin{array}{l}14.59 \\
(6.42)\end{array}$ & & & $\begin{array}{c}42.59 \\
(13.39)\end{array}$ & & & $\begin{array}{c}93.88 \\
(32.07)\end{array}$ & & \\
\hline \multicolumn{11}{|c|}{ Time since spontaneous abortion } \\
\hline 0-6 months & 64 & $\begin{array}{l}12.61 \\
(5.71)\end{array}$ & 2.85 & 0.046 & $\begin{array}{c}40.25 \\
(12.27)\end{array}$ & 1.50 & 0.209 & $\begin{array}{c}78.63 \\
(26.78)\end{array}$ & 2.45 & 0.095 \\
\hline $7-12$ months & 58 & $\begin{array}{c}9.66 \\
(6.51)\end{array}$ & & & $\begin{array}{c}36.12 \\
(21.14)\end{array}$ & & & $\begin{array}{c}68.88 \\
(30.22)\end{array}$ & & \\
\hline $1-2$ years & 64 & $\begin{array}{l}10.97 \\
(6.37)\end{array}$ & & & $\begin{array}{c}37.23 \\
(11.70)\end{array}$ & & & $\begin{array}{c}73.45 \\
(31.90)\end{array}$ & & \\
\hline$>2$ years & 43 & $\begin{array}{c}9.67 \\
(6.83)\end{array}$ & & & $\begin{array}{c}36.53 \\
(11.01)\end{array}$ & & & $\begin{array}{c}64.28 \\
(24.16)\end{array}$ & & \\
\hline \multicolumn{11}{|c|}{ Number of spontaneous abortions } \\
\hline 1 & 150 & $\begin{array}{l}10.86 \\
(5.77)\end{array}$ & 0.24 & 0.785 & $\begin{array}{c}37.10 \\
(11.47)\end{array}$ & 1.04 & 0.381 & $\begin{array}{c}69.25 \\
(26.81)\end{array}$ & 2.86 & 0.068 \\
\hline 2 & 34 & $\begin{array}{l}10.26 \\
(7.28)\end{array}$ & & & $\begin{array}{c}37.12 \\
(12.08)\end{array}$ & & & $\begin{array}{c}72.38 \\
(30.49)\end{array}$ & & \\
\hline$\geq 3$ & 45 & $\begin{array}{l}11.27 \\
(7.69)\end{array}$ & & & $\begin{array}{c}39.96 \\
(13.07)\end{array}$ & & & $\begin{array}{c}80.96 \\
(33.52)\end{array}$ & & \\
\hline \multicolumn{11}{|l|}{ Childlessness } \\
\hline No & 142 & $\begin{array}{l}10.08 \\
(6.02)\end{array}$ & 5.58 & 0.013 & $\begin{array}{c}35.40 \\
(10.69)\end{array}$ & 14.32 & 0.000 & $\begin{array}{c}64.93 \\
(24.66)\end{array}$ & 24.61 & 0.000 \\
\hline Yes & 87 & $\begin{array}{l}12.11 \\
(6.81) \\
\end{array}$ & & & $\begin{array}{c}41.36 \\
(12.85)\end{array}$ & & & $\begin{array}{c}83.59 \\
(31.88)\end{array}$ & & \\
\hline
\end{tabular}

*Non-immigrant; ${ }^{+}$Immigrant

Finally, linear hierarchical regressions were performed to examine the association between the quality of the conjugal relationship, the level of satisfaction with health care, and mental health, while controlling for personal and contextual variables. Since income, schooling level, immigration status, time since spontaneous abortion, and childlessness were significantly associated with depression, anxiety, and perinatal grief, they were included as covariates in the first step of the analysis. To include schooling level, income, and time since spontaneous abortion in the regression analysis, dummy variables were created (income: $0=\leq 49,999,1=\geq 50,000$; schooling level: $0=$ high school, $1=$ college or university; time since 
spontaneous abortion: $0=\leq 6$ months; $1=>6$ months). The results, presented in Table 4, indicated that income was negatively associated with depression, anxiety and perinatal grief, while time since spontaneous abortion was negatively associated with depression and perinatal grief. Schooling was also negatively associated with perinatal grief, while childlessness was positively associated with anxiety and perinatal grief. The results also indicated that, even after controlling for those personal and contextual variables, the quality of the conjugal relationship explained a significant amount of variance in depression, anxiety, and perinatal grief and was significantly negatively associated with those three variables. Finally, even after controlling for all the variables mentioned above, the level of satisfaction with health care added to the prediction of depression and perinatal grief and was significantly and negatively associated with those two variables.

Table 3 - Correlations among the study variables (continuous variables). Québec, Canada, 2018

\begin{tabular}{|c|c|c|c|c|c|c|c|}
\hline Variables & $\begin{array}{l}\text { Gestational } \\
\text { age of the } \\
\text { foetus }\end{array}$ & $\begin{array}{c}\text { Age at } \\
\text { spontaneous } \\
\text { abortion }\end{array}$ & $\begin{array}{l}\text { Quality of } \\
\text { the conjugal } \\
\text { relationship }\end{array}$ & $\begin{array}{c}\text { Satisfaction } \\
\text { with health care }\end{array}$ & Depression & Anxiety & $\begin{array}{l}\text { Perinatal } \\
\text { grief }\end{array}$ \\
\hline \multicolumn{8}{|l|}{$\begin{array}{l}\text { Gestational age of the } \\
\text { foetus }\end{array}$} \\
\hline $\begin{array}{l}\text { Age at spontaneous } \\
\text { abortion }\end{array}$ & $.199^{\dagger}$ & & & & & & \\
\hline $\begin{array}{l}\text { Quality of the conjugal } \\
\text { relationship }\end{array}$ & -.067 & $-.217^{\dagger}$ & & & & & \\
\hline $\begin{array}{l}\text { Satisfaction with health } \\
\text { care }\end{array}$ & .053 & -.015 & .088 & & & & \\
\hline Depression & .085 & .008 & $-.245^{\dagger}$ & $-.287^{\dagger}$ & & & \\
\hline Anxiety & .042 & .054 & $-.292^{\dagger}$ & $-.169^{*}$ & $.727^{\dagger}$ & & \\
\hline Perinatal grief & .070 & .041 & $-.288^{\dagger}$ & $-.265^{\dagger}$ & $.689^{\dagger}$ & $.675^{\dagger}$ & \\
\hline
\end{tabular}

${ }^{*} p<.05,{ }^{+} p<.01$

Table 4 - Linear hierarchical regression analysis for the association between quality of the conjugal relationship, satisfaction with health care and women's mental health, controlling for personal and contextual variables. Québec, Canada, 2018

\begin{tabular}{|c|c|c|c|c|c|c|c|c|c|c|c|c|}
\hline \multirow[t]{2}{*}{ Variables } & \multirow[t]{2}{*}{ B } & \multirow[t]{2}{*}{$p$} & \multicolumn{2}{|c|}{$\begin{array}{c}\text { Depression } \\
95 \% \\
\text { Confidence Interval }\end{array}$} & \multirow[t]{2}{*}{ B } & \multirow[t]{2}{*}{$p$} & \multicolumn{2}{|c|}{$\begin{array}{c}\text { Anxiety } \\
\text { 95\% Confidence } \\
\text { Interval }\end{array}$} & \multirow[t]{2}{*}{ B } & \multirow[t]{2}{*}{$p$} & \multicolumn{2}{|c|}{$\begin{array}{l}\text { Perinatal grief } \\
\text { 95\% Confidence } \\
\text { Interval }\end{array}$} \\
\hline & & & Lower & Upper & & & Lower & Upper & & & Lower & Upper \\
\hline \multicolumn{13}{|l|}{ Step 1} \\
\hline $\begin{array}{l}\text { Income } \\
(\geq 50,000 \mathrm{CAD})\end{array}$ & -.20 & .004 & -4.97 & -0.92 & -.14 & .051 & -7.53 & 0.02 & -.21 & .001 & -22.47 & -5.66 \\
\hline $\begin{array}{l}\text { Schooling (college } \\
\text { or university) }\end{array}$ & -.04 & .512 & -3.09 & 1.54 & -.04 & .583 & -5.54 & 3.12 & -.19 & .003 & -24.27 & -4.99 \\
\hline Immigrant status & .07 & .319 & -1.62 & 4.96 & .03 & .632 & -4.66 & 7.65 & .10 & .121 & -2.87 & 24.50 \\
\hline $\begin{array}{l}\text { Time since } \\
\text { spontaneous } \\
\text { abortion } \\
\text { (> } 6 \text { months) }\end{array}$ & -.17 & .010 & -4.06 & -0.55 & -.11 & .088 & -6.15 & 0.43 & -.12 & .048 & -14.68 & -0.06 \\
\hline Childlessness & .10 & .130 & -0.38 & 2.93 & .22 & .001 & 2.09 & 8.27 & .25 & .000 & 7.53 & 21.28 \\
\hline $\mathrm{R}^{2}$ & .10 & & & & .09 & & & & .21 & & & \\
\hline \multicolumn{13}{|l|}{ Step 2} \\
\hline $\begin{array}{l}\text { Quality of } \\
\text { the conjugal } \\
\text { relationship }\end{array}$ & -.27 & .000 & -0.74 & -0.26 & -.31 & .000 & -1.54 & -0.65 & -.31 & .000 & -3.57 & -1.60 \\
\hline $\mathrm{R}^{2}$ & .17 & & & & .18 & & & & .30 & & & \\
\hline \multicolumn{13}{|l|}{ Step 3} \\
\hline $\begin{array}{l}\text { Satisfaction with } \\
\text { health care }\end{array}$ & -.22 & .001 & -3.32 & -0.91 & -.09 & .153 & -3.93 & 0.62 & -.16 & .007 & -11.86 & -1.94 \\
\hline $\mathrm{R}^{2}$ & .21 & & & & .19 & & & & .32 & & & \\
\hline
\end{tabular}




\section{Discussion}

The main objective of the present study was to identify personal and contextual variables that can represent risk factors for women's mental health after a spontaneous abortion. Specific attention was also given to two potential protective factors: quality of the conjugal relationship and satisfaction with health care. The results showed a high rate of depression among the women in the study. Indeed, half of them could be classified as possibly depressed. This proportion is much higher than the rate of postpartum depression among Canadian women overall $(8.69 \%)^{(31)}$.

The results also indicated that the women who had miscarried within the past 6 months had higher scores for depression than those who had miscarried 7 to 12 months ago. Those results are consistent with previous studies indicating that most women recover from spontaneous abortion within approximately 6 months ${ }^{(32)}$. However, in the present study, the anxiety level and perinatal grief did not vary according to the time since the spontaneous abortion. These results suggest that, for some women, the symptoms persist long after the loss. In fact, there may be several reasons why symptoms of psychological distress and mental health would fluctuate over time, including difficulties conceiving another child, and anniversaries or other significant dates associated with the spontaneous abortion.

Along these lines, a previous study ${ }^{(12)}$ had found that the association between prenatal loss and depression and anxiety did not differ significantly over time and could persist for up to 3 years. A recent study ${ }^{(6)}$ indicated that depressive and grief symptoms persist longer for women who are childless or dissatisfied with the health care services. Future studies should continue on this path and investigate other moderating variables, such as number of spontaneous abortion, age, infertility history, and previous other losses, which might shed light on the conditions under which depression, perinatal grief, and anxiety are likely to resorb more quickly after a spontaneous abortion.

Concerning personal and contextual characteristics, our results suggest that immigrant women, as well as those with a low socioeconomic status and childless women, are particularly vulnerable to mental health problems after a spontaneous abortion. These results are consistent with a previous comprehensive review ${ }^{(33)}$, which identified childlessness as an important contextual variable influencing women's mental health after a spontaneous abortion. However, our results contradict the finding of that review which indicates that the sociodemographic variables were not associated with mental health after a spontaneous abortion. These non- significant results may be due to the fact that past studies used homogenous samples composed of white middleclass married women. Although our sample contained only a small number of immigrants and women with a low socioeconomic status, we were able to identify those two variables as significantly influencing women's mental health.

The results of our study are consistent with a previous study ${ }^{(34)}$ which had found a positive association between schooling level and mental health among women after a spontaneous abortion. However, because no control group was used in the present study, it was not possible to isolate the effect of the spontaneous abortion on those women's mental health in relation to their immigration or socioeconomic status. Also, no data was collected about the mental health of those women before their spontaneous abortions. Nevertheless, it is conceivable that their spontaneous abortions added to other stressors already associated with those personal characteristics ${ }^{(35)}$. As those women may have fewer resources to cope with life stressors ${ }^{(36)}$, they constitute a vulnerable population particularly at risk of developing mental health problems after a spontaneous abortion, and it is clearly necessary to understand their needs and to provide relevant services for them. To clarify those associations, future studies would need to be undertaken with a larger number of immigrant women and women with a low socioeconomic status, along with a control group of women with those same characteristics who did not miscarry.

Women's mental health did not differ according to the number of spontaneous abortions. The results concerning the association between spontaneous abortion history and mental health have been inconsistent ${ }^{(3)}$. The moderating variables could probably explain under which circumstances the number of spontaneous abortions might influence mental health. For example, having experienced a previous pregnancy loss (including a spontaneous abortion) has been associated with poorer mental health during a subsequent pregnancy, but not in the postpartum period following the birth of a live child(37). Thus, the presence of another child seems to moderate the association between a prior loss and mental health.

The results of the linear hierarchical regression indicated that, even after controlling for socioeconomic status, immigrant status and childlessness, the quality of the conjugal relationship explained a significant amount of the variance in depression, anxiety, and perinatal grief, and was negatively associated with those three variables. Thus, women who had miscarried and were satisfied with their relationship experienced better mental health. However, this association could also be bidirectional, such that mental health could in turn influence the quality of the conjugal relationship. 
Indeed, in addition to these repercussions on women's mental health, spontaneous abortions can also impact on the conjugal relationship.

A number of studies have observed a diminished level of satisfaction with the relationship following a perinatal death, which can even ultimately lead to separation or divorce ${ }^{(38-39)}$. The fear of another loss, the mothers' anxiety, and differences in the two spouses' reactions are elements that have been identified( ${ }^{(38)}$ as contributing to conjugal difficulties ${ }^{(40)}$. Unfortunately, the cross-sectional nature of the present study prevented us from testing this hypothesis. Future studies using a longitudinal design could examine the bidirectional nature of the relation between the quality of the conjugal relationship and mental health, and attempt to determine which one is more likely to predict the other. Previous studies have indicated that people who were dissatisfied with their marriages, compared to those who were satisfied with their relationships, were 2.68 times more likely to develop an $\mathrm{MDE}^{(41)}$ (Major Depressive Episode), while our sample was 3.34 times more at risk.

Moreover, even after controlling for sociodemographic variables, childlessness, and quality of the conjugal relationship, the level of satisfaction with health care added to the prediction of depression and perinatal grief. Since many women reported low levels of satisfaction with the health care services after their spontaneous abortion ${ }^{(5-6,17,42)}$, these results highlight the importance of paying particular attention to the quality of the services provided to women before, during, and after a spontaneous abortion. Qualitative studies examining women's experience of a spontaneous abortion have noted that compassion and empathy from health professionals, provision of accurate information (e.g., cause of the loss, physical and emotional symptoms), involvement in treatment decisions, and social support from nurses were identified as particularly helpful(42). These recommendations should be heeded when developing health care services for women who have miscarried.

Finally, our results indicated that the three mental health variables were strongly correlated with each other, indicating a high risk of comorbidity among women having experienced spontaneous abortions. However, personal and contextual variables seemed to be differently associated with those three variables. For example, in the hierarchical regression analysis, childlessness was most strongly associated with perinatal grief than with depression and anxiety when controlling for other sociodemographic factors. This highlights the importance of examining various mental health indicators when studying spontaneous abortions. As noted previously(34), the fact that some women may not present anxiety and depression symptoms after a spontaneous abortion does not mean that they are not struggling with difficult emotions and trying to find meaning in their experience.

One limitation of the present study is its crosssectional design, which does not allow us to comment on the direction of the association between the study variables. For example, it is possible that women with poorer mental health assessed the health care services they received more negatively. Also, since no control group was used, it was not possible to isolate the influence of spontaneous abortions from other risk factors for women's mental health, and the results of the present study should be interpreted cautiously. Nevertheless, the results indicate worrying scores of depression, anxiety and perinatal grief among this sample of women who had experienced a spontaneous abortion in the last 4 years. Finally, the women's histories of prior mental health problems, identified as factors that intensify perinatal bereavement ${ }^{(6,11)}$, and the use of medication or psychotherapy for depression or anxiety were not measured in the present study and might have explained part of the variance in depression, anxiety, and perinatal grief.

Nurses should pay special attention to immigrant women after a spontaneous abortion, in terms of monitoring for mental health issues (e.g., depression, grief, anxiety), and even more so if they have no other children or are living in precarious economic circumstances. Policy makers need to address these issues-for example, by proposing and supporting the implementation of practice guidelines in healthcare services.

\section{Conclusion}

The present study adds to the sparse literature focusing on protective and risk factors for women's mental health after a spontaneous abortion. The results indicate that the symptoms of anxiety, depression, and perinatal grief can persist for a long period after the loss. Also, more attention should be given to women in vulnerable situations, such as immigrant women, women with a low socioeconomic status, or childless women. Beyond those personal and contextual factors, the quality of the conjugal relationship and the level of satisfaction with health care appear to be important protective factors against mental health problems after a spontaneous abortion.

\section{Acknowledgments}

The authors would like to thank Emmanuelle Dennie Fillion, Pascale de Montigny Gauthier, and Jici Lord Gauthier for their support in data collection. We also wish to thank the participating mothers for their generosity with their time in a demanding period of their life. 


\section{References}

1. Engel J, Rempel L. Health Professionals' Practices and Attitudes About Miscarriage. MCN: Am J Matern Child Nurs. 2016;41(1):51-7. doi: 10.1097/NMC. 0000000000000207

2. Zegers-Hochschild F, Adamson GD, Dyer S, Racowsky C, de Mouzon J, Sokol R, et al. The International Glossary on Infertility and Fertility Care, 2017. Fertil Steril. 2017;108(3):393-406. doi: 10.1016/j. fertnstert.2017.06.005

3. de Montigny F, Verdon C, McGrath K. Death, Grief and Culture: Perinatal Death in Canada. In: Cacciatore J, DeFrain J, editors. The World of Bereavement: Cultural Perspectives on Death in Families. New York: Springer; 2015. p. 179-208.

4. Emond T, Montigny F, Guillaumie L. Exploring the needs of parents who experience miscarriage in the emergency department: A qualitative study with parents and nurses. J Clin Nurs. 2019;28(9-10):1952-65. doi: 10.1111/jocn.14780

5. Larivière-Bastien $D$, de Montigny F, Verdon C. Women's Experiences of Miscarriage in the Emergency Department. J Emerg Nurs. 2019;45(6):670-6. doi: 10.1016/j. jen.2019.06.008

6. de Montigny F, Verdon C, Meunier S, Dubeau D. Women's Persistent Depressive and Perinatal Grief Symptoms Following a Miscarriage: the Role of Childlessness and Satisfaction with Health Care Services. Arch Womens Ment Health. 2017;20(5):655-62. doi: 10.1007/s00737-017-0742-9

7. Batool SS, Azam H. Miscarriage: Emotional burden and social suffering for women in Pakistan. Death Stud. 2016;40(10):638-47. doi: 10.1080/07481187.2016.1203376 8. Zhu CS, Tan TC, Chen HY, Malhotra R, Allen JC, Østbye T. Threatened Miscarriage and Depressive and Anxiety Symptoms Among Women and Partners in Early Pregnancy. J Affect Disord. 2018;237:1-9. doi: 10.1016/j. jad.2018.04.012

9. Weng SC, Chang JC, Yeh MK, Wang SM, Lee CS, Chen YH. Do stillbirth, miscarriage, and termination of pregnancy increase risks of attempted and completed suicide within a year? A population-based nested case-control study. BJOG. 2017;125(8):983-90. doi: 10.1111/1471-0528.15105

10. Rowlands I, Lee C. Adjustment after miscarriage: Predicting positive mental health trajectories among young Australian women. Psychol Health Med. 2010;15(1): 34-49. doi: 10.1080/13548500903440239

11. Huffman CS, Schwartz TA, Swanson KM. Couples and Miscarriage: The Influence of Gender and Reproductive Factors on the Impact of Miscarriage. Womens Health Issues. 2015;25(5):570-8. doi: 10.1016/j.whi.2015.04.005
12. Blackmore ER, Côté-Arsenault D, Tang W, Glover V, Evans J, Golding J, et al. Previous prenatal loss as a predictor of perinatal depression and anxiety. $\mathrm{Br} \mathrm{J}$ Psychiatry. 2011;198(5):373-8. doi: 10.1192/bjp.bp.110.083105

13. Campbell-Jackson L, Bezance J, Horsch A. "A renewed sense of purpose": Mothers' and fathers' experience of having a child following a recent stillbirth. BMC Pregnancy Childbirth. 2014;14(1). doi: 10.1186/s12884-014-0423-x 14. Edwards S, Birks M, Chapman Y, Yates K. Bringing Together the 'Threads of Care' in Possible Miscarriage for Women, Their Partners and Nurses in Non-Metropolitan EDs. Collegian. 2018;25(3):293-301.

15. Zeghiche S, de Montigny F, Lopez J. Les variations spatio-temporelles de la (non) reconnaissance sociale du deuil périnatal : Réflexion critique autour du concept de « deuil non reconnu » (disenfranchised grief). Sociologies (en ligne). 2020.

16. Baird S, Gagnon MD, deFiebre G, Briglia E, Crowder $\mathrm{R}$, Prine $\mathrm{L}$. Women's experiences with early pregnancy loss in the emergency room: A qualitative study. Sex Reprod Healthc. 2018;16:113-7. doi: 10.1016/j.srhc.2018.03.001 17. Meaney S, Corcoran P, Spillane N, Donoghue K. Experience of miscarriage: an interpretative phenomenological analysis. BMJ Open. 2017;7(3):e011382. doi: 10.1136/ bmjopen-2016-011382

18. Girard C. Les naissances au Québec et dans les régions en 2018. Québec: Institut de la statistique du Québec; 2019.

19. Cox JL, Holden JM, Sagovsky R. Detection of postnatal depression. Development of the 10-item Edinburgh Postnatal Depression Scale. Br J Psychiatry. 1987; 150:782-6.

20. Guedeney N, Fermanian J. Validation study of the French version of the Edinburgh Postnatal Depression Scale (EPDS): new results about use and psychometric properties. Eur Psychiatry. 1998;13(2):83-9. doi: 10.1007/bf00280883

21. Gauthier J, Bouchard S. A French-Canadian adaptation of the revised version of Spielberger's State-Trait Anxiety Inventory. Can J Behav Sci. 1993;25(4):559-78. doi: $10.1037 /$ h0078881

22. Spielberger $C D$, editor. Manual for the State Trait Anxiety Inventory. Palo Alto: Consulting Psychologists Press; 1983.

23. Potvin L, Lasker J, Toedter L. Measuring grief: A short version of the perinatal grief scale. J Psychopathol Behav Assess. 1989;11(1):29-45. doi: 10.1007/BF00962697

24. de Tychey C, Dollander M. Présentation de I'Échelle de deuil de Potvin, Lasker et Toedter: utilité en clinique pré- et périnatale. Neuropsychiatr Enfance Adolesc. 2000;48(4):245-52.

25. Sabourin S, Valois P, Lussier Y. Development and validation of a brief version of the dyadic adjustment scale with a nonparametric item analysis model. Psychol Assess. 2005;17(1):15-27. doi: 10.1037/1040-3590.17.1.15 
26. Spanier GB. Measuring Dyadic Adjustment: New Scales for Assessing the Quality of Marriage and Similar Dyads. J Marriage Fam. 1976;38(1):15-28.

27. Dubeau D, de Montigny F. Institutional Support Evaluation Scale. 2010.

28. Tabachnick BG, Fidell LS, Ullman JB. Using multivariate statistics. 7th ed. New York: Pearson; 2019.

29. Faul F, Erdfelder E, Lang A-G, Buchner A. G*Power 3: A flexible statistical power analysis program for the social, behavioral, and biomedical sciences. Behavior Research Methods. 2007;39(2):175-91. doi: 10.3758/BF03193146 30. Toedter LJ, Lasker JN, Janssen HJEM. International comparison of studies using the perinatal grief scale: a decade of research on pregnancy loss. Death Studies. 2001;25(3):205-28. doi: 10.1080/07481180125971

31. Lanes A, Kuk JL, Tamim H. Prevalence and characteristics of Postpartum Depression symptomatology among Canadian women: a cross-sectional study. BMC Public Health. 2011;11(1):302. doi: 10.1186/14712458-11-302

32. Lok IH, Yip AS, Lee DT, Sahota D, Chung TK. A 1-year longitudinal study of psychological morbidity after miscarriage. Fertil Steril. 2010;93(6):1966-75. doi: $10.1016 /$ j.fertnstert.2008.12.048

33. Klier CM, Geller PA, Ritsher JB. Affective disorders in the aftermath of miscarriage: A comprehensive review. Arch Womens Ment Health. 2002;5(4):129-49. doi: 10.1007/s00737-002-0146-2

34. Lee C, Rowlands IJ. When mixed methods produce mixed results: integrating disparate findings about miscarriage and women's wellbeing. $\mathrm{Br} \mathrm{J}$ Health Psychol. 2015;20(1):36-44. doi: 10.1111/bjhp.12121

35. Caserta D, Ralli E, Matteucci E, Bordi G, Soave I, Marci $R$, et al. The Influence of Socio-Demographic Factors on Miscarriage Incidence Among Italian and Immigrant Women: A Critical Analysis from Italy. J Immig Minor Health. 2015;17(3):843-51. doi: 10.1007/ s10903-014-0005-z

36. Calderon-Margalit R, Sherman D, Manor O, Kurzweil Y. Adverse Perinatal Outcomes among Immigrant Women from Ethiopia in Israel. Birth. 2015;42(2):125-31. doi: 10.1111/birt.12163
37. Chojenta C, Harris S, Reilly N, Forder P, Austin MP, Loxton D. History of pregnancy loss increases the risk of mental health problems in subsequent pregnancies but not in the postpartum. PLoS One. 2014;9(4):e95038. doi: 10.1371/journal.pone.0095038

38. Tseng YF, Cheng HR, Chen YP, Yang SF, Cheng PT. Grief reactions of couples to perinatal loss: A one-year prospective follow-up. J Clin Nurs. 2017;26(23-24): 5133-42. doi: 10.1111/jocn. 14059

39. Hutti MH, Armstrong DS, Myers JA, Hall LA. Grief Intensity, Psychological Well-Being, and the Intimate Partner Relationship in the Subsequent Pregnancy after a Perinatal Loss. J Obstet Gynecol Neonatal Nurs. 2015;44(1):42-50. doi: 10.1111/1552-6909.12539

40. Zubatsky M, Heiden-Rootes K, Meyer D, Hiefner A. The Impact of Miscarriage on the Quality of the Couple Relationship. Saint Louis University; 2018.

41. Whisman MA, Bruce ML. Marital Dissatisfaction and Incidence of Major Depressive Episode in a Community Sample. J Abnorm Psychol. 1999;108(4):674-8. doi: 10.1037/0021-843X.108.4.674

42. Radford EJ, Hughes M. Women's experiences of early miscarriage: Implications for nursing care. J Clin Nurs. 2015;24(11-12):1457-65. doi: 10.1111/jocn.12781

Received: May 20 2019 Accepted: May $1^{\text {st }} 2020$

Associate Editor: Andrea Bernardes

Copyright $\odot \mathbf{2 0 2 0}$ Revista Latino-Americana de Enfermagem This is an Open Access article distributed under the terms of the Creative Commons (CC BY).

This license lets others distribute, remix, tweak, and build upon your work, even commercially, as long as they credit you for the original creation. This is the most accommodating of licenses offered. Recommended for maximum dissemination and use of licensed materials. 